\title{
How well do patient education materials for Clostridium difficile infection score? A systematic evaluation
}

\author{
Caroline Zellmer, Peggy Zimdars, Sarah Parker, Nasia Safdar \\ University of Wisconsin, United States
}

doi: 10.3396/IJIC.v11i2.010.15

\begin{abstract}
Patient education and engagement is fundamental in the prevention of Clostridium difficile infection (CDI). The usefulness of accessible patient education materials on CDI prevention is uncertain. We undertook a systematic assessment of available materials for patient education on CDI using a validated evaluation tool, the Patient Education Materials Assessment Tool (PEMAT). We found that available materials received low marks on the PEMAT.
\end{abstract}

Keywords: Cross infection; Patient education as topic; Clostridium infections and prevention and control; Patient education handout.

\section{Introduction}

Clostridium difficile infection (CDI) is an increasingly prevalent and severe nosocomial infection, with significant impact on morbidity and mortality as well as length of hospital stay and costs. ${ }^{1,2} \mathrm{C}$. difficile is an anaerobic, gram-positive bacillus that causes diarrhea, colitis, and septicemia, and in many cases, ultimately, death. ${ }^{3}$ According to the CDC, over 107,000 cases of CDI occurred in hospitals in 2011. ${ }^{4}$ Prevention measures include dedicated patient care items and equipment, isolation precautions, environmental decontamination and patient engagement in measures to prevent CDI through education materials. Although a multitude of patient education materials are available for CDI prevention the utility of these educational tools for patients is ambiguous. Furthermore, the understandability and actionability of these materials is unclear. More importantly, the extent to which these materials are of value for the patient is unknown. We performed a systematic assessment of materials for patient education on $\mathrm{CDI}$ using a validated evaluation tool, the Patient Education Materials Assessment Tool (PEMAT).

\section{Corresponding Author \\ Nasia Safdar \\ University of Wisconsin, United States \\ Email: ns2@medicine.wisc.edu}




\section{Methods}

Increasingly, patients utilize online resources to seek information on health care. ${ }^{5}$ We completed an environmental scan for patient education materials on CDI online. Prominent field-relevant search engines such as the Agency for Healthcare Research \& Quality, the Society for Healthcare Epidemiology of America, and Bing, amongst others, were used. Keywords and phrases searched include: $C$. diff patient education materials, C. diff prevention materials, CDC patient education materials about $C$. diff, C. diff Prevention, C. diff, Clostridium difficile prevention, and What Patients can Do to Prevent Clostridium difficile. This uniform scan of common keywords was employed in order to make the scope of the investigation as great as possible. The search was performed on April 23rd, 2014. Materials were included if: they were easily accessible materials seeking to inform patients about the prevention of CDI from public or private healthcare institutions or agencies. In order to determine the understandability and actionability of these education materials, we utilized the PEMAT tool. The PEMAT allows a systematic evaluation of patient education materials by utilizing two series of statements. Seventeen statements are used to determine the understandability, while seven are used to determine the actionability. ${ }^{6}$ Understandability statements evaluate the content of the material, such as the clarity, organization, and use of visual aids. The material is graded on its ability to make the reader familiar with medical terminology as well as its use of quantitative information. Following the United States Department of Health and Human Services guidelines, materials were considered easy to read if they were at a maximum fifth grade reading level. ${ }^{7}$ The materials were also evaluated on the overall organization. Sections over fifty words were considered too long and were given a lower rating for the relevant statement than the more concise alternative. Inclusion of visual aids was rewarded and received superior ratings in the pertinent statement than materials lacking such components. The actionability statements determined the capacity of a material to provide the patient with clear actions to take, use of tangible tools (i.e. checklist), and directly addressing the user when describing the action. Each statement response was rated as either 0 (fail to meet the statement), 1 (satisfied the statement) or $\mathrm{n} / \mathrm{a}$ (not applicable to the material). N/a was only an option for statements that the PEMAT identified as appropriate to select such a response. Three independent reviews were performed to corroborate PEMAT findings. Descriptive statistics were performed using Excel. Inter-evaluator agreement was calculated using the kappa statistics. Disagreement was resolved via consensus.

\section{Results}

We found a total of 19 patient education materials that satisfied our inclusion criteria. The understandability of available patient education materials averaged at 73.4, with a range of scores between 62.7 and 82.9. In contrast, the overall actionability average score was 50.5 with grades ranging from 13 to 73.3 . The majority of materials found did not contain visual aids or any form of a tangible tool (i.e. checklist). A review of the actionability and understandability scores for each of the patient education materials for $C$. difficile infection is located in Table I. The Kappa statistic was 0.8 indicating good agreement between the 3 reviewers.

\section{Discussion}

The poor actionability ratings reflect a general lack of utility of these education materials for the patient. None of the patient education materials evaluated in the scope of this study utilized visual aids, despite patient feedback indicating that patients prefer them over text. ${ }^{8}$ Additionally, visual aids can also serve as a means to enhance the patient-provider dialogue. ${ }^{9}$ Although the understandability ratings are higher on average than the actionability scores the education materials received, there is still significant room for improvement, most commonly in the defining of complex medical terminology.

To improve patient engagement on CDI prevention, several changes can be made to available materials for patient education, including using visual aids, a more specific focus on the preventative measures that engage the patient rather than the healthcare institution. ${ }^{10}$

Our study has limitations. Each review was conducted autonomously, and each evaluator graded the materials based on their own experiences and opinions. For example, the PEMAT requires the evaluator to determine whether or not a material has presented the information in a logical sequence. The potential exists for inter-reviewer disagreement as to whether 
Table I. Rates of Understandability and Actionability of patient education materials for $C$. difficile infection

PEMAT

PEMAT

Actionability Understandability

Site Search/URL

Associated Institution

Rating Rating

\begin{tabular}{lll}
1 & cdc.gov & Cen \\
\hline 2 & picnet.ca
\end{tabular}

Centers for Disease Control

66.7

79.2

Provincial Infection Control

73.3

Network of British Columbia

\begin{tabular}{lllrr}
\hline 3 & online.xplain.com & The Patient Education Institute & 60 & 66.97 \\
\hline 4 & thechristhospital.org & The Christ Hospital Network & 60 & 73.6 \\
\hline 5 & vdh.virginia.gov & Virginia Department of Health & 33 & 62.7 \\
\hline 6 & choa.org & Children's Healthcare of Atlanta & 66.7 & 80.6 \\
\hline 7 & chkd.org & $\begin{array}{l}\text { Children's Hospital of the King's } \\
\text { Daughters }\end{array}$ & 66.7 & 76.2 \\
\hline
\end{tabular}

\begin{tabular}{lllrr}
\hline 8 & mayoclinic.org & The Mayo Clinic & 33 & 74.3 \\
\hline 9 & icpsne.org & $\begin{array}{l}\text { Infection Control Professionals of } \\
\text { Southern New England }\end{array}$ & 66.7 & 79.2 \\
\hline 10 & upmc.org & $\begin{array}{l}\text { University of Pittsburgh Medical } \\
\text { Center }\end{array}$ & 53.3 & 70.2 \\
\hline
\end{tabular}

\begin{tabular}{lllrr}
\hline 11 & mskcc.org & $\begin{array}{l}\text { Memorial Sloan Kettering Cancer } \\
\text { Center }\end{array}$ & 60 & 77.56 \\
\hline 12 & patientsafetyauthority.org & $\begin{array}{l}\text { Pennsylvania Patient Safety } \\
\text { Authority }\end{array}$ & 13 & 68.4 \\
\hline 13 & patientsafetyauthority.org & $\begin{array}{l}\text { Pennsylvania Patient Safety } \\
\text { Authority }\end{array}$ & 33 & 70.63 \\
\hline 14 & virginia.edu & University of Virginia Health System & 60 & 72.6 \\
\hline 15 & effectivehealthcare.ahrq.gov & $\begin{array}{l}\text { Agency for Healthcare Research } \\
\text { and Quality }\end{array}$ & 60 & 63.3 \\
\hline 16 & cdph.ca.gov & $\begin{array}{l}\text { California Department of Global } \\
\text { Health }\end{array}$ & 40 & 80.3 \\
\hline 17 & danburyhospital.org & Danbury Hospital & 46.7 & 82.97 \\
\hline 18 & lahey.org & Lahey Hospital and Medical Center & 46.7 & 77.6 \\
\hline 19 & vdh.virginia.gov & Virginia Department of Health & 20 & 66.3 \\
\hline
\end{tabular}

(Author's note: If there is an error with the link please contact study authors.)

the relative importance of the actions the patient or the hospital can take to prevent the spread of CDI are more important, and subsequently should be presented first.

Despite these limitations, the conclusions from our study can be utilized to guide the development of complete, concise, and applicable materials that facilitate the engagement of the patient in their own recovery and care of $\mathrm{CDI}$.

\section{References}

1. Monge D, Millan I, Gonzalez-Escalada A, Asensio A. The effect of Clostridium difficile infection on length of hospital stay. A cohort study. Enferm Infecc Microbiol Clin 2013; 31(10): 660664. http://dx.doi.org/10.1016/j.eimc.2012.11.007

2. Kyne L, Hamel MB, Polavaram R, Kelly CP. Health care costs and mortality associated with nosocomial diarrhea due to Clostridium difficile. Clin Infect Dis 2002; 34: 346-353. http:// dx.doi.org/10.1086/338260

3. Kelly CP, Pothoulakis C, LaMont TJ. Clostridium difficile colitis. N Engl J Med 1994; 330: 257-262. http://dx.doi.org/10.1056/ NEJM199401273300406 
4. Magill SS, Edwards JR, Bamberg W, et al. Multistate pointprevalence survey of health care-associated infections. N Engl J Med 2014; 370(13): 1198-1208. http://dx.doi.org/10.1056/ NEJMoa1306801

5. Walsh TM, Volsko TA. Readability assessment of internetbased consumer health information. Respir Care 2008; 53(10): 1310-1325.

6. Shoemaker SJ, Wolf MS, Brach C. The Patient Education Materials Assessment Tool (PEMAT). Under Contract No. HHSA290200900012I, TO4. Rockville, MD: Agency for Healthcare Research and Quality; November 2013. AHRQ Publication No. 14-0002-EF.

7. Houts PS, Doak CC, Doak LG, Loscalzo MJ. The role of pictures in improving health communication: a review of research on attention, comprehension, recall and adherence. Patient Educ Couns 2006; 64(1-3): 393-394. http://dx.doi.org/10.1016/j. pec.2006.06.023
8. Mansoor LE, Dowse R. Effect of pictograms on readability of patient information materials. Ann Pharmacother 2003; 37 (78): 1003-1009. http://dx.doi.org/10.1345/aph.1C449

9. Hong J, Nguyen T, Prose N. Compassionate care: Enhancing physician-patient communication and education in dermatology: Part II: Patient education. J Am Acad Dermatol 2013; 69(3): 500.

10. Gudnadottir U, Fritz J, Zerbel S, Bernardo A, Sethi AK, Safdar $\mathrm{N}$. Reducing health care-associated infections: patients want to be engaged and learn about infection prevention. Am J Infect Control 2013; 41(11): 955-958. http://dx.doi.org/10.1016/j. ajic.2013.03.310 